\title{
Methods to Improve Bulk Lifetime in n-Type Czochralski-Grown Upgraded Metallurgical-Grade Silicon Wafers
}

\author{
Rabin Basnet ${ }^{\circledR}$, Fiacre E. Rougieux ${ }^{(\circledR)}$, Chang Sun ${ }^{\circledR}$, Sieu P. Phang, Chris Samundsett, Roland Einhaus, \\ Julien Degoulange, and Daniel Macdonald ${ }^{(1)}$
}

\begin{abstract}
This paper investigates the potential of three different methods-tabula rasa (TR), phosphorus diffusion gettering (PDG), and hydrogenation, for improving the carrier lifetime in n-type Czochralski-grown upgraded metallurgical-grade (UMG) silicon samples. Our results show that the lifetimes in the UMG wafers used in this study were affected by both mobile metallic impurities and as-grown oxygen precipitate nuclei. Thus, the dissolution of grown-in oxygen precipitate nuclei via TR and the removal of mobile impurities via PDG step were found to significantly improve the electronic quality of the UMG wafers. Finally, we report bulk lifetimes and 1-sun implied open-circuit voltages of the UMG wafers after boron and phosphorus diffusions, as typically applied in n-type cell fabrication.
\end{abstract}

Index Terms-Czochralski (Cz), hydrogenation, phosphorus diffusion gettering, tabula rasa, upgraded metallurgical-grade (UMG) silicon.

\section{INTRODUCTION}

$\mathbf{N}$ -TYPE upgraded metallurgical-grade (UMG) silicon is a promising low-cost feedstock material for high-efficiency silicon solar cells [1]-[4]. Conventional silicon wafers used in solar cell fabrication are based on electronic grade (EG) feedstock, with a high level of purity [5]. However, UMG feedstocks are purified using various hydrometallurgical routes and therefore have a higher concentration of metallic and nonmetallic impurities [2], [6]-[8] in comparison with EG silicon purified via the Siemens process [9].

Furthermore, during the growth of Czochralski $(\mathrm{Cz})$ ingots from UMG feedstocks, the agglomeration of supersaturated interstitial oxygen into precipitate nuclei can be enhanced by the presence of impurities [10] in comparison with $\mathrm{Cz}$ ingots grown

Manuscript received February 15, 2018; revised April 16, 2018; accepted May 7, 2018. Date of publication June 7, 2018; date of current version June 19, 2018. This work has been supported by the Australian Renewable Energy Agency (ARENA) through research grant RND009. (Corresponding author: Rabin Basnet.)

R. Basnet, F. E. Rougieux, C. Sun, S. P. Phang, C. Samundsett, and D. Macdonald are with the Research School of Engineering, The Australian National University, Canberra, ACT 2601, Australia (e-mail: rabin.basnet@anu.edu. au; fiacre.rougieux@anu.edu.au; chang.sun@anu.edu.au; pheng.phang@ anu.edu.au; chris.samundsett@anu.edu.au; daniel.macdonald@ anu.edu.au).

R. Einhaus and J. Degoulange are with the Apollon Solar, 69002 Lyon, France (e-mail: einhaus@apollonsolar.com; degoulange@ apollonsolar.com).

Color versions of one or more of the figures in this paper are available online at http://ieeexplore.iee.org.

Digital Object Identifier 10.1109/JPHOTOV.2018.2834944 with EG feedstock. This can result in a higher grown-in oxygen precipitate nuclei density in $\mathrm{UMG} \mathrm{Cz}$ wafers compared with EG $\mathrm{Cz}$ wafers. Grown-in oxygen precipitate nuclei can lead to ring defects after certain high-temperature processing steps [11], [12]. Ring defects are primarily caused by recombination active oxygen precipitates [13] and their associated extended defects [14]. Their recombination activity can be further increased by mobile metallic impurity decoration [14], interactions with intrinsic point defects (vacancies and self-interstitials) [10], and the presence of carbon [15], [16]. Given that UMG Cz wafers contain a higher concentration of both metallic and nonmetallic impurities, in addition to the grown-in oxygen precipitates, the recombination activity of ring defects in UMG $\mathrm{Cz}$ wafers, and their response to solar cell processing steps, may be markedly different to that of EG Cz wafers.

In this paper, we explore several methods to reduce the impact of recombination sources such as mobile metallic impurities and oxygen precipitates in UMG Cz wafers. The processes are-tabula rasa (TR), phosphorus diffusion gettering (PDG), and hydrogenation $(\mathrm{H})$. A high-temperature preannealing step known as a tabula rasa can be used to dissolve the grown-in oxygen precipitate nuclei [17], which can mitigate the formation of ring defects during subsequent high-temperature treatments. In addition, PDG step can be used to remove mobile metallic impurities [18], [19]. Furthermore, hydrogenation can also be implemented to passivate ring defects [12], [20].

The purpose of this study is to examine the effectiveness of these three methods for improving bulk lifetimes during hightemperature processing of $\mathrm{UMG} \mathrm{Cz}$ wafers, both in isolation and in combination with each other. In addition, the integration of these methods into a typical process sequence for fabricating high-efficiency passivated emitter rear and totally diffused (PERT) or passivated emitter and rear locally diffused (PERL) [21] n-type solar cells, including boron diffusion, is examined.

We note that the compensated nature of n-type $\mathrm{Cz}$ UMG wafers can result in a strong degradation of final cell performance under illumination, due to the presence of the well-known boron-oxygen-related defects [22]-[24], and that these defects can be at least partially deactivated by annealing under illumination [25]. However, this study is solely focused on the impact of high-temperature steps, and does not consider boron-oxygen defects. 
TABLE I

WAFER PROPERTIES OF THE N-TYPE CZ SAMPLES USED IN THIS WORK

\begin{tabular}{|c|c|c|c|c|c|c|c|c|}
\hline Ingot position & $\begin{array}{c}\text { Solidified } \\
\text { fraction }\left(f_{s}\right)\end{array}$ & $\begin{array}{c}\text { Resistivity } \\
(\Omega . \mathrm{cm})\end{array}$ & $\begin{array}{c}{[\mathrm{B}]} \\
\left(\mathrm{cm}^{-3}\right)\end{array}$ & $\begin{array}{c}{[\mathrm{P}]} \\
\left(\mathrm{cm}^{-3}\right)\end{array}$ & $\begin{array}{l}\text { Net doping } \\
\left(n_{o}\right)\left(\mathrm{cm}^{-3}\right)\end{array}$ & $\begin{array}{c}\text { Thickness } \\
(\mu \mathrm{m})\end{array}$ & $\begin{array}{c}{\left[\mathrm{O}_{\mathrm{i}}\right]} \\
\left(\mathrm{cm}^{-3}\right)\end{array}$ & $\begin{array}{c}{[\mathrm{C}]} \\
\left(\mathrm{cm}^{-3}\right)\end{array}$ \\
\hline UMG Seed & 0.04 & 3.1 & $9.8 \times 10^{15}$ & $1.0 \times 10^{16}$ & $2.0 \times 10^{14}$ & 180 & $7.5 \times 10^{17}$ & $4.2 \times 10^{16}$ \\
\hline UMG Middle & 0.25 & 2.4 & $1.1 \times 10^{16}$ & $1.2 \times 10^{16}$ & $1.0 \times 10^{15}$ & 180 & $6.5 \times 10^{17}$ & $6.2 \times 10^{16}$ \\
\hline UMG Tail & 0.7 & 0.6 & $1.3 \times 10^{16}$ & $2.0 \times 10^{16}$ & $7.0 \times 10^{15}$ & 180 & $6.2 \times 10^{17}$ & $1.2 \times 10^{17}$ \\
\hline EG Control & & 1.0 & & $5.0 \times 10^{15}$ & $5.0 \times 10^{15}$ & 275 & $5.7 \times 10^{17}$ & $<1 \times 10^{15}$ \\
\hline
\end{tabular}

\section{EXPERIMENTAL METHODS}

The UMG feedstock was produced by FerroPem and the $\mathrm{Cz}$ ingot and wafers used in this work were produced by Apollon Solar (ingot number ISO10) in the framework of the PHOTOSIL project [1]. The length of the ingot was $573 \mathrm{~mm}$ after cropping and the weight was $67 \mathrm{~kg}$. The wafers were categorized into three groups-seed, middle, and tail depending on their position in the ingot (or solidified fraction, $f_{s}$ ). The dopant densities of both phosphorus and boron and the total carbon concentrations within the compensated UMG $\mathrm{Cz}$ wafers and control wafers were measured by secondary ion mass spectrometry. The relative interstitial oxygen concentrations were measured by Fourier transform infrared spectroscopy measurements with a Bruker Vertex 80 tool. The measurements were calibrated using SEMI MF standard 1188-1107. The control wafers used in this study were uncompensated n-type EG $\mathrm{Cz}$ silicon wafers. The solidified fractions, resistivities, dopant concentrations, wafer thicknesses, interstitial oxygen concentrations $\left[\mathrm{O}_{\mathrm{i}}\right]$ and total carbon concentrations [C] are summarized in Table I.

The samples used in this study were laser cut from 6 inch pseudosquare UMG $\mathrm{Cz}$ wafers. The 4 inch round control wafers were diced into four quarters for lifetime measurements. All samples were saw damage etched with tetramethylammonium hydroxide (TMAH) solution to remove 10-12 $\mu \mathrm{m}$ from each side, before standard cleaning steps prior to further processing.

The optimization of a TR step in this work was performed in an oxygen ambient at various temperatures between $950{ }^{\circ} \mathrm{C}$ and $1100{ }^{\circ} \mathrm{C}$ for 15 to $120 \mathrm{~min}$ with loading and unloading at 700 ${ }^{\circ} \mathrm{C}$ and ramp up and down rates of a $15{ }^{\circ} \mathrm{C} / \mathrm{min}$. Some of the samples with the optimal TR step then underwent a PDG step after removing the oxide layer with an HF dip. The PDG step was performed for $30 \mathrm{~min}$ at $785^{\circ} \mathrm{C}$ with phosphorus oxychloride $\left(\mathrm{POCl}_{3}\right)$ as the dopant source, resulting in a sheet resistance of $90-100 \Omega / \square$. Furthermore, to demonstrate the effectiveness of the aforementioned three methods of bulk lifetime improvements in relation to n-type PERT/PERL cell fabrication, boron diffusions were applied to some samples prior to the PDG step. The boron diffusions were performed for 40 min using a boron tribromide $\left(\mathrm{BBr}_{3}\right)$ dopant source at a temperature of $950{ }^{\circ} \mathrm{C}$, with an additional $10 \mathrm{~min}$ postoxidation, to achieve a sheet resis- tance of 50-60 $\Omega / \square$. The diffused layers were then removed by a short HF dip and TMAH etch before any subsequent treatments.

For lifetime measurements, Radio Corporation of America (RCA) cleaned wafers were passivated with silicon nitride $\left(\mathrm{SiN}_{\mathrm{x}}: \mathrm{H}\right)$ layers using plasma enhanced chemical vapor deposition (Roth and Rau AK400) with a sample temperature of approximately $300{ }^{\circ} \mathrm{C}$.

Hydrogenation of some of the $\mathrm{SiN}_{\mathrm{x}}: \mathrm{H}$ coated samples was performed using a rapid thermal annealing system (Unitemp UTP-1100) under a nitrogen ambient at a sample temperature of $500{ }^{\circ} \mathrm{C}$ for $10 \mathrm{~s}$ with a ramp rate of $25^{\circ} \mathrm{C} / \mathrm{s}$. Hydrogenated UMG samples were stripped of their $\mathrm{SiN}_{\mathrm{x}}: \mathrm{H}$ layers by dipping in an HF solution, and given a short TMAH etch to remove a few microns of silicon. Subsequently, these samples were repassivated with fresh $\mathrm{SiN}_{\mathrm{x}}: \mathrm{H}$ layers to allow measurement of the lifetimes after hydrogenation.

Photoluminescence (PL) images were captured using an LISR1 PL imaging tool from BT imaging [26], with an illumination intensity of 0.5 suns. PL images with different exposure times were normalized to yield the PL count rate per second, which allows relative comparison from sample to sample. Also, carrier lifetime measurements were performed using the quasi steadystate photoconductance and transient photoconductance decay techniques with a WCT-120 tool from Sinton Instruments [27]. The carrier lifetime was determined using carrier mobility values for compensated silicon from Schindler's mobility model [28]. The lifetimes are reported at an excess carrier density of $1 \times 10^{15} \mathrm{~cm}^{-3}$. The data points in each plot represent a single sample for each condition.

\section{RESULTS AND DISCUSSIONS}

In the following, we first report the results for the optimization of TR conditions for the UMG samples, in Section III-A. In Section III-B, we then examine the bulk lifetimes of the samples after phosphorus diffusion gettering, with and without a prior TR step. Section III-C, then investigates the impact of hydrogenation on phosphorus gettered samples with and without a prior TR step. Finally, in Section III-D, we demonstrate the response of the UMG wafers to typical processing sequences for n-type PERT/PERL cells, including boron diffusions, with and without these three methods for bulk lifetime improvement. 


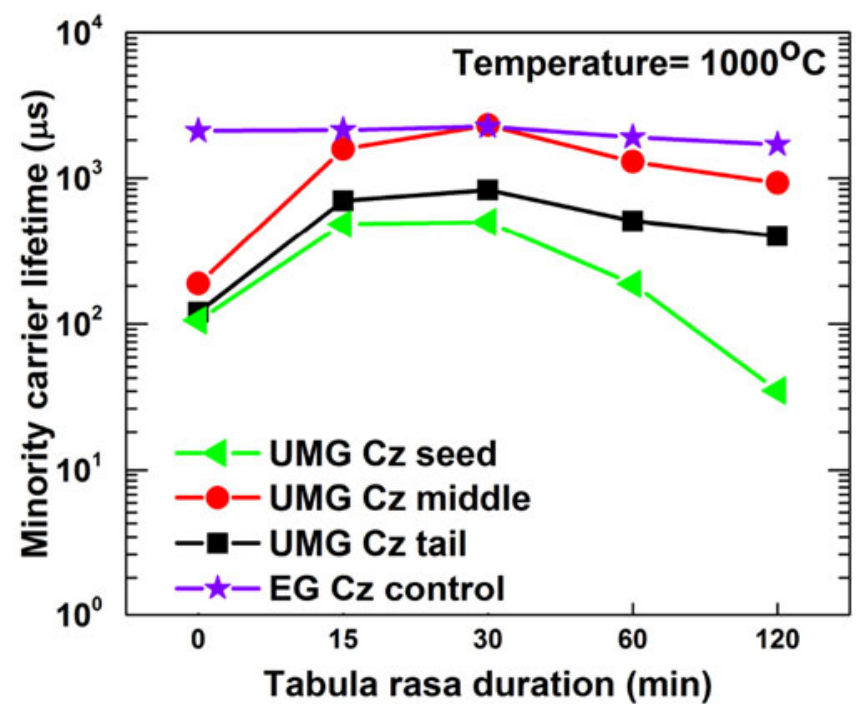

(a)

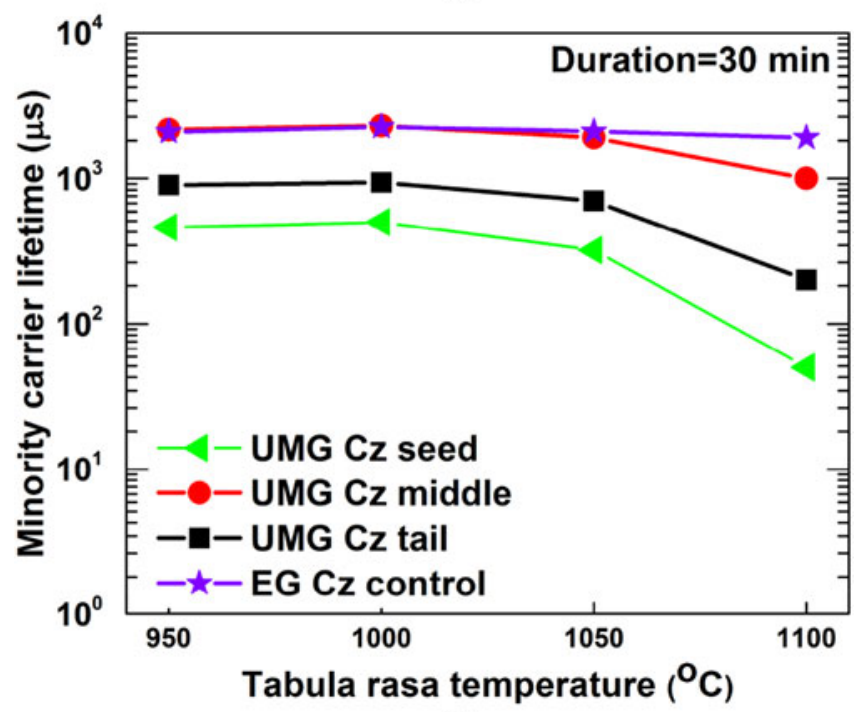

(b)

Fig. 1. Minority carrier lifetimes at an injection level of $1 \times 10^{15} \mathrm{~cm}^{-3}$ for the UMG Cz wafers from three different positions of the ingot and the $\mathrm{EG} \mathrm{Cz}$ control samples. (a) Isothermal TR treatment of $1000^{\circ} \mathrm{C}$ as a function of time, with as-grown lifetimes shown as $0 \mathrm{~min}$. (b) Isochronal TR treatment of $30 \mathrm{~min}$ as a function of temperature.

\section{A. Tabula Rasa}

The optimal TR temperature and duration depends on the size and distribution of the oxygen precipitates in the as-grown wafers [29]. In order to determine the optimum temperature and duration of the TR treatment, samples cut from the same wafer were treated at four different temperatures and durations, as shown in Fig. 1.

For all of the TR conditions used in this study, the bulk lifetimes of the UMG samples were higher for samples from the middle, whereas the samples from the seed end had the lowest lifetimes. For all three ingot positions of the UMG ingot, the bulk lifetimes decreased as the TR temperatures increased above $1000{ }^{\circ} \mathrm{C}$ and for durations longer than $30 \mathrm{~min}$. However, the degradation was greater for samples from the seed end in comparison with the middle and tail end of the ingot. Furthermore, samples from the seed end developed ring defects for all of the TR conditions performed in this work. However, the bulk lifetimes of the middle and tail end of the UMG wafers improved after the TR treatments in comparison with as-grown lifetime. Moreover, no ring defects were present in both the middle and tail end samples, as shown in Fig. 2. Note that the control samples had stable bulk lifetimes and no ring defects for all the TR conditions (not shown), except for a slight reduction in lifetime after $120 \mathrm{~min}$ of annealing. Thus, we conclude that a TR condition of $1000{ }^{\circ} \mathrm{C}$ for $30 \mathrm{~min}$ is optimal for the UMG $\mathrm{Cz}$ wafers in this work.

\section{B. Phosphorus Diffusion Gettering}

Phosphorus diffusion gettering was performed on two sets of samples, the first with no previous thermal processing, and the second with the optimal TR treatment of $1000{ }^{\circ} \mathrm{C}$ for $30 \mathrm{~min}$ applied prior to a PDG step.

Bulk lifetimes in both sets of the samples increased significantly after the PDG step in comparison with the as-grown samples, as shown in Fig. 3(a). The first group of the UMG samples with no prior TR step developed ring defects after phosphorus diffusion, as shown in Fig. 2. This might be due to the presence of a higher density of grown-in oxygen precipitate nuclei, as the UMG wafers have relatively high carbon concentrations, as shown in Table I, and carbon has been shown to enhance oxygen precipitation [16]. Furthermore, carbon might act as nucleation sites [30] for additional oxygen precipitate formation during the PDG step. In addition, there might be further growth of pre-existing oxygen nuclei [17] during the PDG step, increasing their recombination activity. Nevertheless, despite the emergence of the ring defects, phosphorus gettering reduced the overall recombination activity of the samples compared with the as-grown state, as shown in Fig. 3(a). However, the samples from the middle and tail end of the UMG ingot, from the second group with a prior TR step, showed no ring defects after PDG step, whereas the sample from the seed end still contained ring defects after PDG step, as shown in Fig. 2. The EG control samples showed no ring defects (not shown) and the bulk lifetime improved by a smaller extent. These results suggest that the lifetime of the UMG samples is significantly affected by both mobile impurities and oxygen precipitate nuclei.

The relative recombination center density reduction $\left(N_{t}^{*}\right)$ was then determined, as defined by $\left(N_{t}^{*}\right)=1 / \tau_{\text {before gettering }-}$ $1 / \tau$ after gettering. $N_{t}^{*}$ represents the reduction in the effective recombination center density due to the PDG step. Fig. 3(b), shows the relative concentration of lifetime-affecting impurities removed by a PDG step for both sets of samples. $N_{t}^{*}$ is much greater in the UMG samples than in the EG control sample. Interestingly, the concentration of lifetime-limiting impurities removed by the PDG step is similar for UMG wafers with or without a previous TR treatment. This suggests that any mobile 


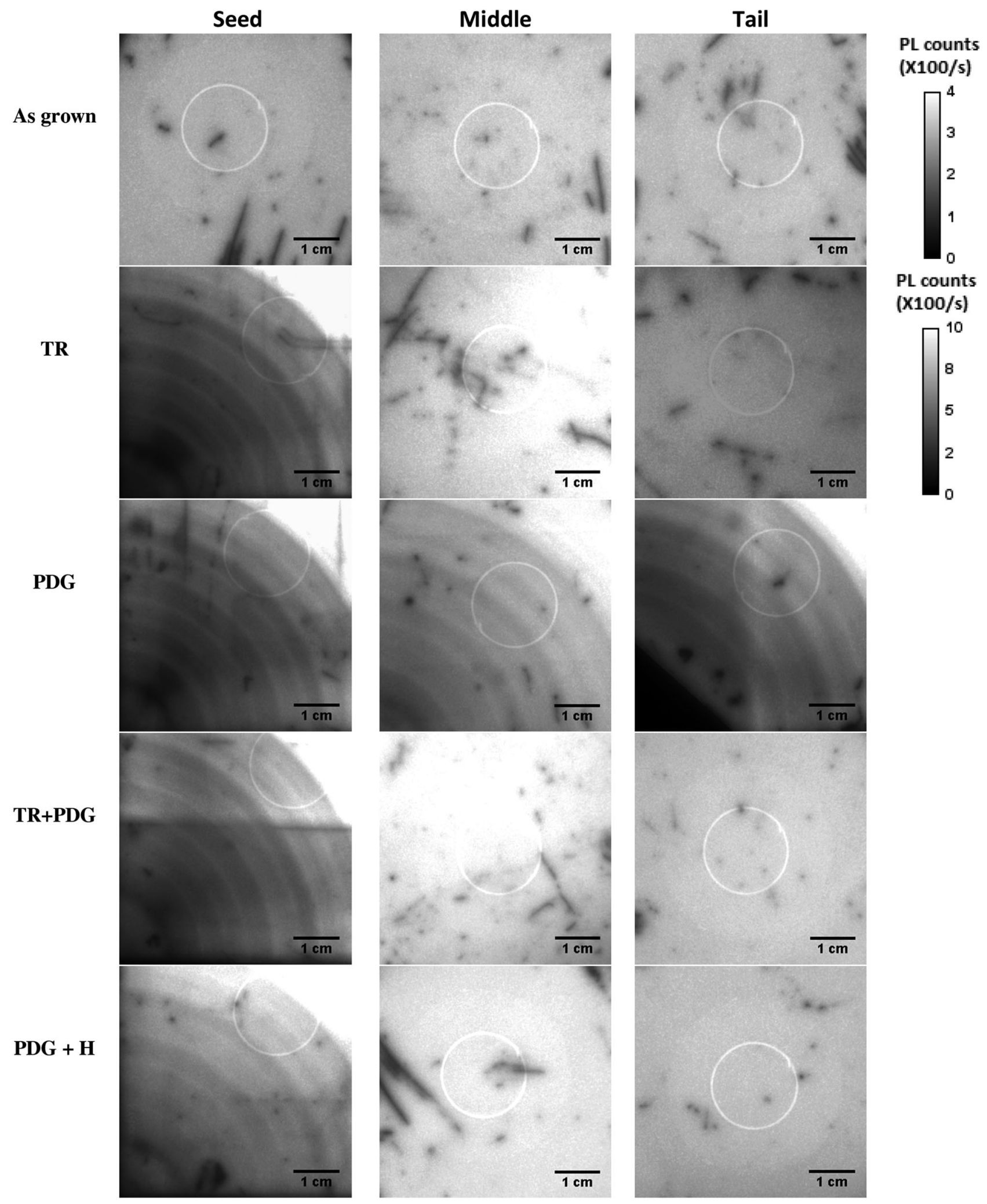

Fig. 2. PL images of the UMG Cz wafers from three different positions of the ingot which show the effect of TR, PDG, and $\mathrm{H}$ in isolation and in combination, in comparison with the as-grown state. A scale bar shown in the first row is for the as-grown samples and in the second row is for all other samples. All of the images were captured at constant illumination intensity of 0.5 suns and normalized to PL counts/second. The bright circle in the images is an artifact due to the conductance coil in the PL imaging tool. 


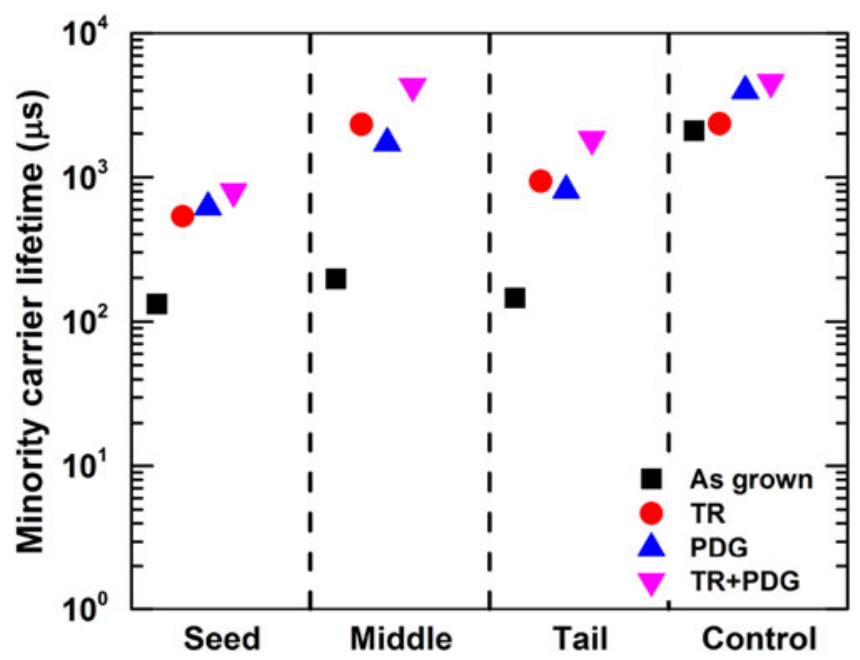

(a)

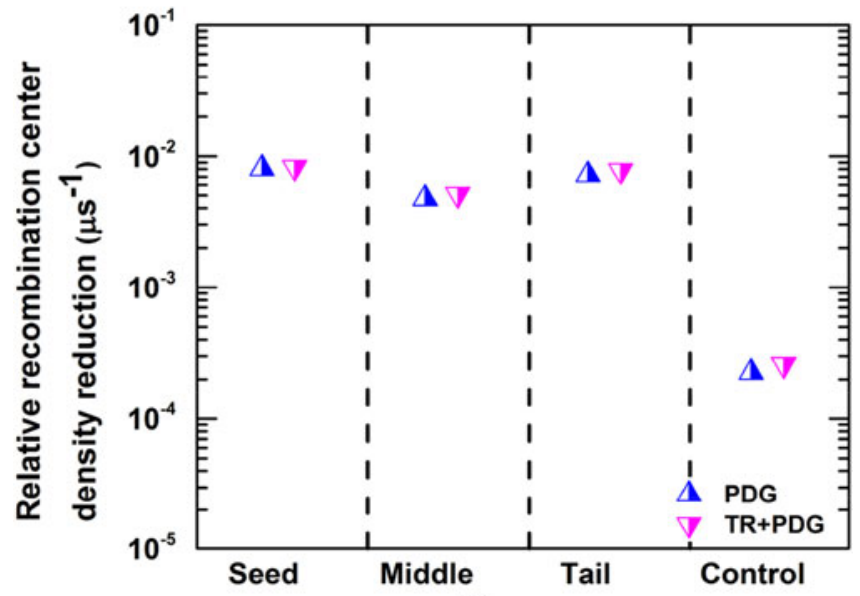

(b)

Fig. 3. (a) Minority carrier lifetimes at an injection level of $1 \times 10^{15} \mathrm{~cm}^{-3}$ for the UMG wafers from three different position of the ingot and control wafers after TR and PDG steps both in isolation and in combination. (b) Relative recombination center density reduction due to the PDG step for the UMG samples from three different positions of ingot and the EG $\mathrm{Cz}$ control samples.

impurities released from oxygen precipitates during the TR step are effectively removed by the gettering step [31], and therefore do not significantly impact the lifetimes of the wafers.

\section{Hydrogenation}

Hydrogenation was performed for the UMG and EG control samples divided into two groups as mentioned in Section III-B, first with only a PDG step beforehand and second with both TR and PDG steps (TR+PDG). The first group of the UMG samples contains ring defects, as shown above in the PL images in Fig. 2, although not in the control wafer. This group of the UMG samples $(\mathrm{PDG}+\mathrm{H})$ showed improved bulk lifetimes after hydrogenation, as plotted in Fig. 4. However, the PL images revealed that the hydrogenation was able to passivate the ring defects only in the middle and tail UMG samples, as shown in Fig. 2. The UMG sample from the seed end had residual ring defects even after hydrogenation.

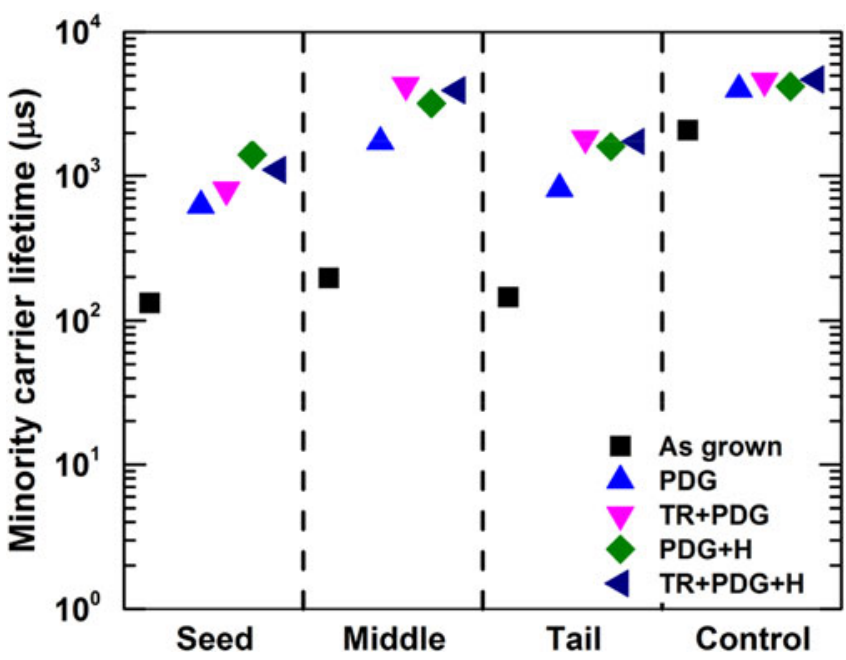

Fig. 4. Minority carrier lifetimes for the UMG Cz wafers from three different positions of the ingot and $\mathrm{EG} \mathrm{Cz}$ control wafers at an injection level of $1 \times 10^{15} \mathrm{~cm}^{-3}$ for various combinations of PDG, TR, and $\mathrm{H}$.

The lifetimes of the samples from the middle and tail end of the UMG ingot and the control of the second group $(\mathrm{TR}+\mathrm{PDG}+\mathrm{H})$ were similar before and after hydrogenation. However, the lifetime of the seed UMG sample, improved after hydrogenation, even though residual ring defects exist, as shown in the PL images in Fig. 2. Thus, in these UMG samples, the effect of lifetime-affecting oxygen precipitates can be reduced by both TR and hydrogenation step. However, hydrogenation step is only beneficial, if there are residual ring defects to be passivated.

In this study, none of the three methods were able to entirely remove the ring defects from the seed end of the UMG ingot. During $\mathrm{Cz}$ silicon crystal growth, the concentration of oxygen in the melt and consequent incorporation at the solidmelt interface is affected by several factors, including the rate of dissolution of the silica crucible walls and evaporation from the melt surface [32], [33]. During Cz crystal growth, this typically leads to a decreasing concentration of oxygen from the seed end to tail end of the ingot, as we see in this study. Thus, persistent ring defects in the seed end may be partly ascribed to a higher concentration of dissolved oxygen, causing formation of a higher density or larger sized oxygen precipitates. Furthermore, this part of an ingot typically experiences a lower cooling rate which could further enhance the oxygen precipitation. In addition, during crystal growth, the seed end of an ingot is usually rich in vacancies [34], [35]. High vacancy concentrations enhance oxygen precipitation by absorbing the strain during the growth of oxygen precipitates [36]-[38]. This may also lead to a higher density of oxygen precipitate nuclei in the seed end of the ingot.

\section{Potential for High-Efficiency Solar Cells}

High-efficiency "PERT" or "PERL" [39] solar cells fabricated with n-type silicon wafers require both boron and phosphorus diffusions at high temperature to allow electrical contact to the 


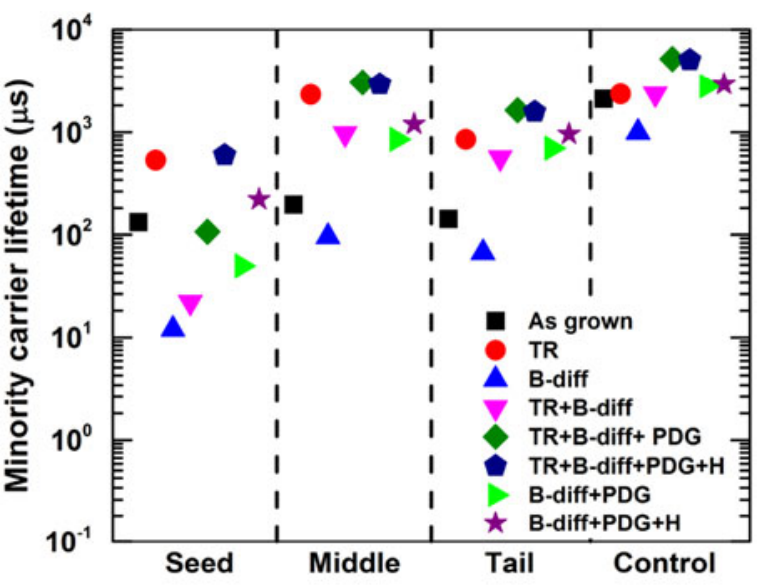

(a)

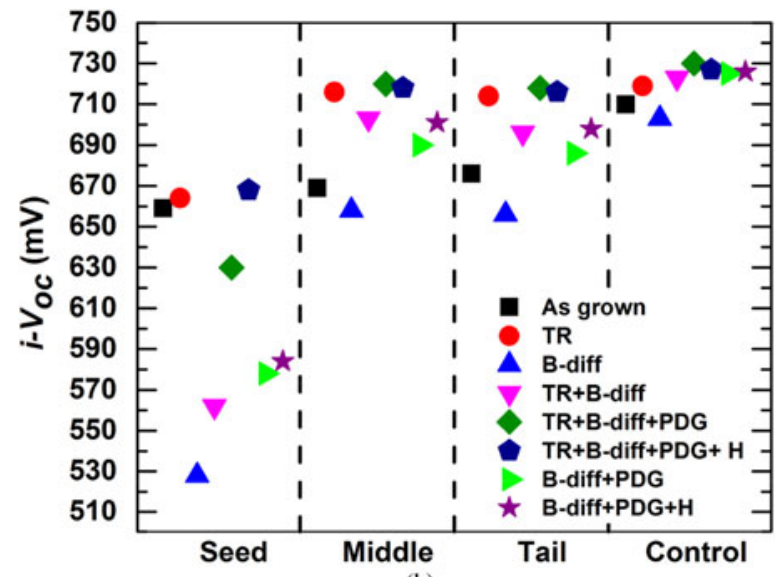

(b)

Fig. 5. Evolution of the (a) bulk lifetimes and (b) implied open-circuit voltages, $i-V_{\mathrm{oc}}$ at 1 sun, of the UMG Cz wafers from three different positions of the ingot and EG Cz control wafers for various combinations of TR, B-diff, PDG, and $\mathrm{H}$ steps.

device. As we have seen above, the bulk lifetimes can be significantly affected by such high-temperature processes. For this reason, we next investigate the impact of a typical sequence of such high-temperature steps on the bulk lifetimes and implied 1-sun open-circuit voltages for samples from each part of the UMG $\mathrm{Cz}$ ingot, in comparison with the EG $\mathrm{Cz}$ control samples. This enables an assessment of the potential of such n-type UMG Cz wafers for high-efficiency cells, when the benefits of TR, PDG, and $\mathrm{H}$ steps are included.

After boron diffusion (B-diff), the bulk lifetimes of all the wafers were degraded below the as-grown lifetimes, as shown in Fig. 5(a). This degradation may be due to either process contamination, since a boron diffusion with in situ oxidation does not protect very well against impurities from the furnace [1], or other defects already within the wafers which are activated during the boron diffusion. After boron diffusion, the ring defects were present in the UMG wafers, but not in the control wafer. This suggests that the control wafer was more likely degraded due to process contamination rather than oxygen precipitates, whereas the UMG wafers were likely degraded from both process contamination and the nucleation of new oxygen precipitates and/or activation of pre-existing oxygen precipitates, as mentioned in Section III-B.

Furthermore, in this study, the ring defects in the UMG wafers after boron and phosphorus diffusions were not completely passivated by the subsequent hydrogenation. Nevertheless, the bulk lifetimes increased after PDG and hydrogenation steps. However, employing a TR step, prior to the boron diffusion step, the middle and tail UMG wafers showed no ring defects, but the seed end wafers showed residual ring defects. Hence, a TR step prior to any subsequent thermal treatment processes is a robust method of preventing ring defects for the middle and tail UMG $\mathrm{Cz}$ wafers used in this study. Similarly, as observed in Section III-C, hydrogenation does not provide additional benefits when the ring defects are removed by a prior TR step.

Furthermore, after a PDG step of the TR and boron diffused samples $(\mathrm{TR}+\mathrm{B}$-diff $+\mathrm{PDG})$, the bulk lifetimes improved significantly to $3,1.6$, and $5.2 \mathrm{~ms}$ for the middle and tail UMG and the EG control samples, respectively, as shown in Fig. 5(a). Similarly, the implied $V_{\mathrm{oc}}$ of the middle and tail UMG the control samples for the same process combination, were 720,718 , and $730 \mathrm{mV}$, respectively, as shown in Fig. 5(b). Thus, including an optimized TR step, the middle and tail UMG wafers are almost equivalent in electronic quality to the EG control wafers for the typical high-efficiency solar cell process.

\section{CONCLUSION}

In this paper, three different methods of improving bulk lifetimes-TR, PDG, and $\mathrm{H}$ in n-type UMG $\mathrm{Cz}$ wafers were investigated. For the UMG Cz wafers used in this study, the bulk lifetimes were affected by oxygen precipitates, mobile metallic impurities, and carbon. Thus, the dissolution of grown-in oxygen precipitate nuclei via TR and the removal of mobile impurities via a PDG step are critical for the UMG wafers in comparison with EG $\mathrm{Cz}$ control wafers. However, wafers from the seed end of the UMG ingot had persistent ring defects even after TR and PDG steps. Hydrogenation improved the bulk quality of the seed wafers to some extent, but their lifetimes and implied open-circuit voltages remained well below those of the middle and tail UMG wafers.

In the best cases, bulk lifetimes in excess of 4.2 and $3 \mathrm{~ms}$ were achieved for wafers from the middle and tail end of the UMG ingot, respectively, after performing a TR step prior to a PDG step (TR+PDG). Furthermore, performing a TR step prior to boron and phosphorus diffusions, bulk lifetimes in excess of 3 and $1.7 \mathrm{~ms}$, and implied open-circuit voltages of 720 and 718 $\mathrm{mV}$ were achieved for wafers from the middle and tail end of the UMG ingot, respectively. These results are very promising for processing of high-efficiency PERT or PERL cells using UMG Cz wafers.

\section{REFERENCES}

[1] J. Kraiem et al., "High performance solar cells made from 100\% umg silicon obtained via the photosil process," in Proc. Conf. Rec. IEEE Photovolt. Spec. Conf., 2010, pp. 1427-1431.

[2] F. Rougieux et al., "High efficiency UMG silicon solar cells: Impact of compensation on cell parameters," Prog. Photovolt. Res. Appl., vol. 24, no. 5, pp. 725-734, 2016. 
[3] P. Zheng et al., "Simulation of 20.96\% efficiency n-type Czochralski UMG silicon solar cell," Energy Procedia, vol. 92, pp. 434-442, 2016.

[4] P. Zheng et al., "21.1\% UMG silicon solar cells," IEEE J. Photovolt., vol. 7, no. 1, pp. 58-61, Jan. 2017.

[5] S. Pizzini, "Towards solar grade silicon: Challenges and benefits for low cost photovoltaics," Sol. Energy Mater. Sol. Cells, vol. 94, no. 9, pp. 1528$1533,2010$.

[6] W. Lee et al., "Metal impurities behaviors of silicon in the fractional melting process," Sol. Energy Mater. Sol. Cells, vol. 95, no. 1, pp. 59-62, 2011.

[7] A. Peral, J. Manuel Míguez, R. Ordás, and C. Del Cañizo, "Lifetime improvement after phosphorous diffusion gettering on upgraded metallurgical grade silicon," Sol. Energy Mater. Sol. Cells, vol. 130, pp. 686-689, 2014.

[8] R. Einhaus, J. Kraiem, S. Martinuzzi, and M. C. Record, "PHOTOSIL Simplified production of solar silicon from metallurgical silicon," in Proc. 21 st Eur. Photovolt. Sol. Energy Conf., 2006, pp. 580-584.

[9] A. Luque and S. Hegedus, Handbook of Photovoltaic Science and Engineering. Hoboken, NJ, USA: Wiley, 2011.

[10] V. V. Voronkov and R. Falster, "Intrinsic point defects and impurities in silicon crystal growth," J. Electrochem. Soc., vol. 149, no. 3, p. G167G174, 2002.

[11] K. Marsden, S. Sadamitsu, T. Yamamoto, and T. Shigematsu, "Generation of oxidation-induced stacking faults in Czochralski-grown silicon crystals exhibiting a ring-like distributed stacking fault region," Jpn. J. Appl. Phys., vol. 34, no. 6R, pp. 2974-2980, 1995.

[12] G. Coletti et al., "Removing the effect of striations in n-type silicon solar cells," Sol. Energy Mater. Sol. Cells, vol. 130, pp. 647-651, 2014.

[13] E. Cartier, J. H. Stathis, and D. A. Buchanan, "Passivation and depassivation of silicon dangling bonds at the $\mathrm{Si} / \mathrm{SiO}_{2}$ interface by atomic hydrogen," Appl. Phys. Lett., vol. 63, no. 11, pp. 1510-1512, 1993.

[14] J. D. Murphy, K. Bothe, V. V. Voronkov, and R. J. Falster, "On the mechanism of recombination at oxide precipitates in silicon," Appl. Phys. Lett., vol. 102, no. 4, 2013, Art. no. 042105.

[15] P. Liu, X. Ma, J. Zhang, L. Li, and D. Que, "Evidence for the effect of carbon on oxygen precipitation in Czochralski silicon crystal," J. Appl. Phys., vol. 87, 2000, Art. no. 3669.

[16] S. Zhang, M. Juel, E. J. Vrelid, and G. Tranell, "Investigating the effect of carbon on oxygen behavior in n-type Czochralski silicon for PV application," J. Cryst. Growth, vol. 411, pp. 63-70, 2015.

[17] M. P. Robert J. Falster, M. Cornara, D. Gambaro, and M. Olmo, "Effect of high temperature pre-anneal on oxygen precipitates nucleation kinetics in Si," Solid State Phenom., vol. 57-58, pp. 123-128, 1997.

[18] S. P. Phang and D. Macdonald, "Boron, phosphorus and aluminum gettering of iron in crystalline silicon: Experiments and modelling," in Proc.Conf. Rec. IEEE Photovolt. Spec. Conf., 2010, pp. 352-356.

[19] V. Osinniy et al., "Gettering improvements of minority-carrier lifetimes in solar grade silicon," Sol. Energy Mater. Sol. Cells, vol. 101, pp. 123-130, 2012.

[20] B. Hallam, C. Chan, M. Abbott, and S. Wenham, "Hydrogen passivation of defect-rich n-type Czochralski silicon and oxygen precipitates," Sol. Energy Mater. Sol. Cells, vol. 141, pp. 125-131, 2015.

[21] M. A. Green, Silicon Solar Cells Advanced Principles and Practice. Sydney, NSW, Australia: Centre PV Device and Syst., Univ. New South Wales, 1995.

[22] F. E. Rougieux et al., "Influence of net doping, excess carrier density and annealing on the boron oxygen related defect density in compensated n-type silicon," J. Appl. Phys., vol. 110, no. 6, 2011, Art. no. 063708.

[23] F. E. Rougieux et al., "Recombination activity and impact of the boronoxygen-related defect in compensated N-type silicon," IEEE J. Photovolt., vol. 1, no. 1, pp. 54-58, Jul. 2011.
[24] T. Schutz-Kuchly, J. Veirman, S. Dubois, and D. R. Heslinga, "Lightinduced-degradation effects in boron-phosphorus compensated n -type Czochralski silicon," Appl. Phys. Lett., vol. 96, no. 9, 2010, Art. no. 122103.

[25] P. Zheng et al., "Upgraded metallurgical-grade silicon solar cells with efficiency above 20\%," Appl. Phys. Lett., vol. 108, no. 12, 2016, Art. no. 122103.

[26] T. Trupke, R. Bardos, M. Schubert, and W. Warta, "Photoluminescence imaging of silicon wafers," Appl. Phys. Lett., vol. 89, no. 4, 2006, Art. no. 044107.

[27] R. A. Sinton and A. Cuevas, "Contactless determination of currentvoltage characteristics and minority-carrier lifetimes in semiconductors from quasi-steady-state photoconductance data," Appl. Phys. Lett., vol. 69, no. 17 , pp. $2510-2512,1996$.

[28] F. Schindler et al., "Modeling majority carrier mobility in compensated crystalline silicon for solar cells," Sol. Energy Mater. Sol. Cells, vol. 106, pp. 31-36, 2012.

[29] E. E. Looney et al., "Oxygen migration enthalpy likely limits oxide precipitate dissolution during tabula rasa," Appl. Phys. Lett., vol. 111, no. 13, 2017, Art. no. 132102.

[30] F. Shimura, "Carbon enhancement effect on oxygen precipitation in Czochralski silicon," J. Appl. Phys., vol. 59, no. 9, pp. 3251-3254, 1986.

[31] J. D. Murphy, R. E. McGuire, K. Bothe, V. V. Voronkov, and R. J. Falster, "Competitive gettering of iron in silicon photovoltaics: Oxide precipitates versus phosphorus diffusion," J. Appl. Phys., vol. 116, no. 5, 2014, Art. no. 053514 .

[32] S. Maeda and K. Terashima, "Macroscopic uniformity of oxygen concentration in Czochralski silicon crystals closely related to evaporation of $\mathrm{SiO}$ from the free surface of melts," J. Electrochem. Soc., vol. 150, pp. G319-G326, 2003.

[33] K. Hoshikawa and X. Huang, "Oxygen transportation during Czochralski silicon crystal growth," Mater. Sci. Eng. B, vol. 72, nos. 2/3, pp. 73-79, 2000

[34] T. Abe and T. Takahashi, "Intrinsic point defect behavior in silicon crystals during growth from the melt: A model derived from experimental results," J. Cryst. Growth, vol. 334, no. 1, pp. 16-36, 2011.

[35] V. V. Voronkov and R. Falster, "Intrinsic point defects and grown-in microdefects in silicon crystals-comment on: "Intrinsic point defect behaviour in silicon crystals during growth from the melt: A model derived from experimental results," T. Abe, T. Takahashi, Journal of Crystal Growth 334 (2011) 16," J. Cryst. Growth, vol. 351, no. 1. pp. 115-117, 2012.

[36] H. Zimmermann and R. Falster, "Investigation of the nucleation of oxygen precipitates in Czochralski silicon at an early stage," Appl. Phys. Lett., vol. 60, no. 26, pp. 3250-3252, 1992.

[37] V. V. Voronkov and R. Falster, "Effect of vacancies on nucleation of oxide precipitates in silicon," Mater. Sci. Semicond. Process., vol. 5, nos. 4/5, pp. 387-390, 2002.

[38] V. V. Voronkov and R. Falster, "Vacancy-type microdefect formation in Czochralski silicon," J. Cryst. Growth, vol. 194, no. 1, pp. 76-88, 1998.

[39] S. P. Phang, W. Liang, B. Wolpensinger, M. A. Kessler, and D. MacDonald, "Tradeoffs between impurity gettering, bulk degradation, and surface passivation of boron-rich layers on silicon solar cells," IEEE J. Photovolt., vol. 3, no. 1, pp. 261-266, Jan. 2013.

Authors' photographs and biographies not available at the time of publication. 